\title{
COMMevtaRy On this month's Round the Corner: I welcome the argument about $\mathrm{ECT}^{\dagger}$
}

\author{
John Read (10)
}

\begin{abstract}
John Read, PhD, is Professor of Clinical Psychology in the School of Psychology at the University of East London, UK. He is Chair of the International Institute for Psychiatric Drug Withdrawal, and on the Board of the Hearing Voices Network,

England. He has been the editor of the journal Psychosis for 11 years and has authored or co-authored over 150 research papers and several books. Correspondence John Read. Email: john@uel.ac.uk
\end{abstract}

First received 15 Apr 2021 Accepted 14 May 202

\section{Copyright and usage}

(c) The Author(s), 2021.

${ }^{\dagger}$ Commentary on... Electroconvulsive therapy (ECT) versus sham ECT for depression (Round the Corner). See this issue.

\section{SUMMARY}

A recent review of research in electroconvulsive therapy (ECT) for depression, for which I was the first author, found that only 11 placebo-controlled studies have even been conducted, all pre-1986. Our review concluded that they were so flawed that the meta-analyses that relied on them were wrong to conclude that ECT is effective. This commentary responds to a critique of the review by lan Anderson. Some valuable comments are acknowledged and several errors or misunderstandings rectified.

\section{KEYWORDS}

Electroconvulsive therapy (ECT); placebo; efficacy; evidence-based medicine; depression.

I thank Ian Anderson (2021, this issue) for critiquing our 40-page review (Read 2019) of placebo-controlled ECT trials for depression and the meta-analyses based on those trials. He makes some valuable points. The 24-point quality scale we developed to evaluate the trials probably should have been analysed in relation to different aspects of quality rather than just reported as a total score. Our summary of the research demonstrating memory loss and brain damage (Sackeim 2007; Fosse 2013; Read 2019, 2021a) was, indeed, brief.

\section{Criticism of the review's methods}

\section{Placebo-controlled studies}

Dr Anderson claims that we positioned placebo-controlled studies as the 'only' method to evaluate efficacy. We actually wrote: 'ECT must be assessed using the same standards applied to psychiatric medications and other medical interventions, with placebo-controlled studies as the primary method for assessment'

Given the disturbingly poor quality of the placebo studies (all 11 were pre-1986), ECT advocates turn to non-placebo studies for support. Our review acknowledged: 'The many recent studies that either compare ECT to other treatments, or compare different types of ECT with each other, typically open with an unqualified statement that ECT is a very effective treatment for depression'. However, an earlier review, which found more than 2500 non-placebo ECT studies, concluded that even the best 91 studies failed to produce any 'robust evidence that ECT is effective for depression, primarily because at least $60 \%$ maintained ECT participants on medication, 89\% produced no meaningful follow-up data beyond the end of treatment, and none investigated whether ECT prevents suicide' (Read 2017).

\section{Quality criteria}

Dr Anderson describes some of our quality criteria as 'idiosyncratic'. If criteria such as suicide, quality of life measure and patients' ratings are considered peculiar, that speaks volumes about what he and his colleagues think is acceptable to exclude. Other criteria are 'not explained'. Explaining why 'sample sizes of ten or more' and 'follow-up data' are desirable might have seemed condescending.

All 24 quality criteria were operationalised with explicit definitions, tested by the interrater reliability process.

Dr Anderson writes 'There is no description of the criteria by which the robustness of the meta-analyses was assessed'. These are clearly stated: 'The metaanalyses were evaluated primarily in terms of whether they considered the quality of the studies they included, but also in terms of whether they addressed efficacy beyond end of treatment'.

\section{The evidence}

Dr Anderson acknowledges that there is 'next to no evidence' on long-term benefits. Our review demonstrated that there has never been any evidence that ECT outperforms placebo beyond the end of treatment.

Nor is there any evidence that ECT prevents suicide, as is so often claimed. In a study published since our review, 14810 patients receiving ECT were 1.3 times more likely to die by suicide than 58369 non-ECT controls (Peltzman 2020).

Dr Anderson cites the latest meta-analysis (Mutz 2019), ignoring its being based on only one ECT study, which the authors themselves deemed at 'high risk' for bias. 
How can ECT advocates deny that ECT causes brain damage when an ECT machine manufacturer lists 'permanent brain damage and permanent memory loss' as risks? (Somatics 2018).

\section{Campaigning for better research and regulation}

Dr Anderson bemoans the fact that the review "has been used to support a campaign headed by the lead author for the suspension of ECT' (Read 2020a), without mentioning that the stated purpose is to allow time for 'a series of well designed, randomized, placebo-controlled studies' (Read 2019).

Following confirmation that ECT remains inadequately monitored and regulated in England (Read 2018, 2021b; Harrop 2021) the campaign is calling for an independent enquiry by the government (Johnstone 2020). This has widespread support, including from the UK's largest mental health charity, Mind (Buckley 2020), the Royal College of Nursing, the Association of Clinical Psychologists, Headway (the brain injury association) and the Shadow Minister for Mental Health (Allin-Khan 2020, 2021).

\section{Tone and Approach}

Dr Anderson includes a section entitled 'Tone and approach'. We are accused of being 'adversarial'. Examples include our suggesting that the meta-analyses involved 'carelessness, bias or both', the exact same words used by Anderson to characterise our own work. The words 'being forced to undergo ECT after stating that you do not want it', to describe the experience of one in three ECT recipients in England (Read 2018, 2021b), are portrayed as 'misleading'. The term 'Brain damaging therapeutics' is presented as an example of our being 'emotive', without disclosing that these were not our words at all but the title of an early paper arguing that ECT works because it reduces brain functioning (Freeman 1941). I am not sure where Dr Anderson's depicting our work as a 'polemic dressed in the clothes of a scientific review' falls on his 'tone and approach' spectrum. But I enjoyed his hutzpah, given that the review's second author is Irving Kirsch, Associate Director of Placebo Studies at Harvard Medical School.

Professor Kirsch has commented:

'I don't think many ECT advocates understand just how strong placebo effects are for a major procedure like ECT. The failure to find any meaningful longterm benefits compared to placebo groups is particularly distressing. On the basis of the clinical trial data, ECT should not be used for depressed individuals' (cited in Read 2020b).

\section{Conclusions}

Dr Anderson was actually relatively constructive and restrained. His one or two mischievous, but eloquent, taunts stand in stark contrast to the plethora of malicious attacks, on social media and elsewhere, from pro-ECT psychiatrists, targeting the authors, their professions, the journal and even the platforms, such as Psychology Today (Read 2020b), Aeon (Read 2021c) and Medscape (Vlessides 2020), that had the audacity to publish summaries of the review. It was amid the most virulent torrent of such fear and loathing, on Medscape, that one woman was brave enough to write:

\begin{abstract}
'My long-term memory was destroyed. Memories of childhood friends, memories of major events I attended, memories of my training as a psychiatric registrar. I started struggling with simple spelling and calculations. [...] I never told colleagues about this, as I felt ashamed. But I started talking to other people who had ECT and realized I am not alone. I can understand some of the negative responses by colleagues to this article, but I have to admit that

I welcome the argument' (cited in Vlessides 2020).
\end{abstract}

\section{Data availability}

Data availability is not applicable as no new data were created or analysed.

\section{Author contribution}

J.R. was the sole contributor to this article.

\section{Funding}

This article involved no grant from any funding agency, commercial or not-for-profit.

\section{Declaration of interest}

None.

\section{References}

Allin-Khan R (2020) Question for Department of Health and Social Care. Electroconvulsive Therapy. 30 0ct 2020. UK Parliament (https://members. parliament.uk/member/4573/writtenquestions?page=2).

Allin-Khan R (2021) Question for Department of Health and Social Care. Electroconvulsive Therapy: Regulation. 19 Feb 2021. UK Parliament (https://members.parliament.uk/member/4573/writtenquestions? page=2)

Anderson I (2021) Electroconvulsive therapy (ECT) versus sham ECT for depression: do study limitations invalidate the evidence (and mean we should stop using ECT)? BJPsych Advances, this issue.

Buckley S (2020) Mind is backing a call to review the use of Electroconvulsive Therapy (ECT). Mind (https://www.mind.org.uk/news-cam paigns/news/mind-is-backing-a-call-to-review-the-use-of-electroconvulsivetherapy-ect//)

Fosse R, Read J (2013) Electroconvulsive treatment: hypotheses about mechanisms of action. Frontiers in Psychiatry, 4: 94-103.

Freeman W (1941) Brain-damaging therapeutics. Diseases of the Nervous System, 2: 83.

Harrop C, Read J, Geekie J, et al (2021) How accurate are ECT patient information leaflets provided by mental health services in England and 
the Royal College of Psychiatrists? An independent audit. Ethical Human Psychology and Psychiatry, in press.

Johnstone L, Cunliffe S (2020) Guest blog: Call for an independent review into the practice of ECT. Council for Evidence Based Psychiatry (http:// cepuk.org/2020/09/07/blog-call-for-an-independent-review-into-the-practice-of-ect/).

Mutz J, Vipulananthan V, Carter B, et al (2019) Comparative efficacy and acceptability of non-surgical brain stimulation for the acute treatment of major depressive episodes in adults: systematic review and network meta-analysis. BMJ, 364: I1079.

Peltzman T, Shiner B, Watts B (2020) Effects of electroconvulsive therapy on short-term suicide mortality in a risk-matched patient population. Journal of ECT, 36: 187-92.

Read J, Arnold C (2017) Is electroconvulsive therapy for depression more effective than placebo? A systematic review of studies since 2009. Ethical Human Psychology and Psychiatry, 19: 5-23.

Read J, Harrop C, Geekie J, et al (2018) An audit of ECT in England 20112015: usage, demographics, and adherence to guidelines and legislation. Psychology and Psychotherapy: Theory, Research and Practice, 91: 263-77.

Read J, Kirsch I, McGrath L (2019) Electroconvulsive therapy for depression: a review of the quality of ECT versus sham ECT trials and meta-analyses. Ethical Human Psychology and Psychiatry, 21: 64-103.

Read J, Kirsch I, Cunliffe S, et al (2020a) Call for immediate suspension of electroconvulsive therapy in NHS trusts pending research into efficacy and safety. Open letter to: Peter Wyman, Chair of the Care Quality Commission (2 Jul). Available from: https://www.uel.ac.uk/Staff/r/john-read.

Read J (2020b) 80 years on, do we know if electroconvulsive therapy works? Psychology Today (https://www.psychologytoday.com/gb/blog/ psychiatry-through-the-looking-glass/202008/80-years-do-we-know-if-electroconvulsive-therapy).

Read J, Hancock S, Cunliffe S (2021a) ECT: dangerous on either side of the pond. Psychiatric Times, 38: 4-7.

Read J, Harrop C, Geekie J, et al (2021b) A second independent audit of electroconvulsive therapy in England, 2019: usage, demographics, consent, and adherence to guidelines and legislation. Psychology and Psychotherapy: Theory, Research and Practice [Epub ahead of print] 16 Mar. Available from: https://bpspsychub.onlinelibrary.wiley.com/doi/10. 1111/papt.12335.

Read J (2021c) Shocked. Aeon (https://aeon.co/essays/why-is-electroshock-therapy-still-a-mainstay-of-psychiatry).

Sackeim H, Prudic J, Fuller R, et al (2007) The cognitive effects of ECT in community settings. Neuropsychopharmocology, 32: 244-54.

Somatics (2018) Regulatory Update to Thymatron System IV Instruction Manual. Somatics LLC (http://www.thymatron.com/downloads/System_IV_ Regulatory_Update.pdf).

Vlessides M (2020) Experts call for immediate suspension of ECT, others push back. Medscape (https://www.medscape.com/viewarticle/ 934536). 